OPEN ACCESS

Edited by:

Hajar Maleki,

University of Cologne, Germany

Reviewed by:

Yutie Bi,

Southwest University of Science and

Technology, China

Sheng Cui,

Nanjing Tech University, China

Yong Kong,

Nanjing Tech University, China

${ }^{*}$ Correspondence:

Bin Zhou

zhoubin863@tongji.edu.cn

Ai Du

duai@tongji.edu.cn

Specialty section:

This article was submitted to

Polymeric and Composite Materials,

a section of the journal

Frontiers in Materials

Received: 01 March 2021

Accepted: 31 May 2021

Published: 29 June 2021

Citation:

Niu T, Zhou B, Zhang Z, Yang J, Ji X, Shen J, Zhang $Z$ and Du A (2021)

Synthesis of Monolithic $\mathrm{TiO}_{2}$ Aerogels With Relatively Low Shrinkage and

Improved Formability Assisted

by CTAB.

Front. Mater. 8:674578.

doi: 10.3389/fmats.2021.674578

\section{Synthesis of Monolithic $\mathrm{TiO}_{2}$ Aerogels With Relatively Low Shrinkage and Improved Formability Assisted by CTAB}

\author{
Tingting Niu ${ }^{1,2}$, Bin Zhou ${ }^{1,2 *}$, Zehui Zhang ${ }^{1,2}$, Jianming Yang ${ }^{1,2}$, Xiujie $\mathrm{Ji}^{1,2}$, Jun Shen ${ }^{1,2}$, \\ Zhihua Zhang ${ }^{1,2}$ and $\mathrm{Ai} \mathrm{Du}^{1,2 *}$
}

${ }^{1}$ School of Physics Science and Engineering, Tongji University, Shanghai, China, ${ }^{2}$ Shanghai Key Laboratory of Special Artificial Microstructure Materials and Technology, Tongji University, Shanghai, China

Monolithic $\mathrm{TiO}_{2}$ aerogels without severe shrink were obtained by the sol-gel method with the addition of the surfactant cetyltrimethylammonium bromide (CTAB) to control the hydrolysis and polycondensation process and acetonitrile solvent as the solvent to improve the crystallinity. After $\mathrm{CO}_{2}$ supercritical drying, the shrinkage ratio of monolithic $\mathrm{TiO}_{2}$ aerogels modified by CTAB decreased by up to $26.9 \%$, compared with the pure $\mathrm{TiO}_{2}$ aerogel. Their apparent densities were all lower than $300 \mathrm{~g} / \mathrm{cm}^{3}$. X-ray Diffraction (XRD), Scanning Electron Microscopy (SEM), Transmission Electron Microscopy (TEM), Fourier Transform infrared spectroscopy (FTIR) and BET Specific Surface Area Analysis were used to analyze the assynthesized samples. The results revealed that all the samples were anatase- $\mathrm{TiO}_{2}$ phase with nanoporous network structures. The specific surface areas reached $250.2 \mathrm{~m}^{2} / \mathrm{g}$ confirmed by the BET (Brunaur-Emmett-Teller method) analysis. However, $\mathrm{TiO}_{2}$ aerogels without the addition of CTAB showed evident agglomeration and collapse of the network in comparison with CTAB-added samples. To further study the structureproperty relationship, the photocatalysis performance of as-synthesized and $300^{\circ} \mathrm{C}$-calcined aerogels was carried out contrastively. Interestingly, the influences of the CTAB adding amount of as-synthesized and calcined $\mathrm{TiO}_{2}$ aerogels are negative and positive, respectively, which is probably due to the synergistic effect of CTAB hindrance and grain refinement. Potentially, This kind of $\mathrm{TiO}_{2}$ aerogels assisted by CATB with low density, small shrinkage, improved formability, high specific surface area and fine crystalline grain may be applied in various applications, such as electrochemistry, photocatalysis, etc.

Keywords: $\mathrm{TiO}_{2}$ aerogel, CTAB, sol-gel, monolithic, low shrinkage, formability

\section{INTRODUCTION}

Nano- $-\mathrm{TiO}_{2}$ materials have become a widely concerned research topic worldwide due to their excellent semiconductor properties (Chen, 2009; Muniz et al., 2011; Noman et al., 2019; Xie et al., 2019). Photocatalysis is one of the most popular topics (Znaidi et al., 2001; Topcu et al., 2016; Guo et al., 2018; Sanjay et al., 2019), and its efficiency is primarily affected by the specific surface area and grain size. To improve the photocatalytic effect, $\mathrm{TiO}_{2}$ powder doped into different materials was discussed in previous studies (Anucha et al., 2021; Bathula et al., 2021). As aerogel is a kind of material with high specific surface area and large porosity(Wen et al., 2018; Yan et al., 2018; Bi et al., 2019; Wen et al., 2020), it is a better choice 
to study the photocatalysis of $\mathrm{TiO}_{2}$ aerogel (Moussaoui et al., 2017; Qingge et al., 2018; Zhang et al., 2018). However, it is tough to prepare a kind of $\mathrm{TiO}_{2}$ aerogel with low density and high porosity. The pure $\mathrm{TiO}_{2}$ gel is very easy to shrink during the aging and drying process and easy to re-dissolve during the replacement process. Therefore, it is widely believed that molding the $\mathrm{TiO}_{2}$ aerogel, fragile and easy to shrink, is really challenging.

Due to the fragile network, it is beneficial to combine $\mathrm{TiO}_{2}$ aerogel with another nanomaterial to have more stable nanostructure and excellent porosity (Cheng et al., 2016; Xiang et al., 2018; Luna et al., 2020; Liu et al., 2021). Zu et al. have found that the composite aerogel obtained by combining $\mathrm{SiO}_{2}$ and $\mathrm{TiO}_{2}$ has good moldability and a superior photocatalytic effect (Zu et al., 2015). The $\mathrm{TiO}_{2}$ /carbon composites have also been well studied as photocatalysts since carbon acted as a scaffold (Martins et al., 2017; Parale et al., 2019). An excellent supporting template can increase the formability and specific surface area, thereby further enhancing the photocatalytic performance. As a surfactant, cetyltrimethylammonium bromide (CTAB) has a perfect poreforming effect and could play the role of framework support. There have been many studies on the addition of CTAB to improve the performance of $\mathrm{TiO}_{2}$ gel since it can effectively increase the specific surface area (Zhong et al., 2013; Wu et al., 2018; Dong et al., 2020). However, $\mathrm{TiO}_{2}$ aerogel requires subsequent heat treatment to improve its crystallinity (Baia et al., 2006), which removes CTAB (Nadrah et al., 2017) and causes a severe collapse of the pore structure and limits the improvement of photocatalytic performance. It is necessary to find a way to avoid the calcination in order to obtain a kind of $\mathrm{TiO}_{2}$ aerogel with larger specific surface area, as well as better formability. Studies have shown that the selected solvent can improve the crystallinity of $\mathrm{TiO}_{2}$ aerogels (Hu et al., 1992). Therefore, if the traditional solvent ethanol is replaced by another solvent, it is possible to avoid the disadvantages of high-temperature treatment and make the aerogel obtained by supercritical drying have good crystallinity and improved formability.

In our work, we chose acetonitrile as the solvent, added different amounts of CTAB in the sol-gel process, and successfully obtained bulk $\mathrm{TiO}_{2}$ aerogels with good formability and high porosity. This is a simple method by sol-gel process to prepare $\mathrm{TiO}_{2}$ aerogel without the assistance of any other inorganic material. The combination of $\mathrm{CTAB}$ and acetonitrile realized to get a kind of monolithic $\mathrm{TiO}_{2}$ aerogel with better formability, lower density and higher porosity. To further understand the role of $\mathrm{CTAB}$, we also compared the differences in the aerogels' microstructure before and after heat treatment and the changes in photocatalytic performance.

\section{EXPERIMENTS}

\section{Materials}

All the reagents, including acetonitrile $\left(\mathrm{AR}, 99.0 \%, \mathrm{CH}_{3} \mathrm{CN}\right)$, acetic acid (AR, 99.5\%, $\left.\mathrm{CH}_{3} \mathrm{COOH}\right)$, concentrated nitric acid (65.0-68.0\%, $\left.\mathrm{HNO}_{3}\right)$, tetrabutyl titanate (CP, 98.0\%, Ti $\left.\left(\mathrm{OC}_{4} \mathrm{H}_{9}\right)_{4}\right)$, cetyltrimethylammonium bromide $(\mathrm{CP}, 98.0 \%$, $\left.\mathrm{C}_{16} \mathrm{H}_{33} \mathrm{~N}\left(\mathrm{CH}_{3}\right)_{3}-\mathrm{Br}, \mathrm{CTAB}\right)$, and ethanol, were purchased from
Sinopharm Chemical Reagent Co., Ltd. (Shanghai, China) and used without further purification.

\section{Preparation of $\mathrm{TiO}_{2}$ Aerogels}

In our work, we used tetrabutyl titanate as the precursor, acetonitrile as the solvent, acetic acid as the inhibitor, concentrated nitric acid as the $\mathrm{pH}$ value modifier, and a small amount of deionized water as well as CTAB to produce the $\mathrm{TiO}_{2}$ aerogel. Different amounts (as shown in Table 1) of cetyltrimethylammonium bromide (CTAB) were dissolved in $30 \mathrm{ml}$ of acetonitrile and $4.5 \mathrm{ml}$ of distilled water at room temperature (RT) to achieve colorless transparent solution A, which was ready to adjust the microstructure of $\mathrm{TiO}_{2}$ gel, especially the pore-size distribution. $6 \mathrm{ml}$ of acetic acid, $450 \mu \mathrm{l}$ of concentrated nitric acid, and $12 \mathrm{ml}$ of tetrabutyl titanate were added successively into $30 \mathrm{ml}$ of acetonitrile at $0^{\circ} \mathrm{C}$ in an ice bath to achieve pale yellow semitransparent solution $\mathrm{B}$. The $\mathrm{pH}$ value of solution $\mathrm{B}$ was about 1 . After stirring for $15 \mathrm{~min}$, solution A was poured slowly into solution B. It is worth noting that the gelation time was shorter if more $\mathrm{CTAB}$ was added. Hence, the uniform mixture must be transferred to a proper container (such as plastic capsules) before it gelled. Its color turned opaque milk-white after the gelation process at room temperature. The wet gel was sealed and aged for 2 days, then removed and repeatedly substituted by acetonitrile every $8 \mathrm{~h}$ for 6 times to remove water and residual chemicals. At last, it was dried by $\mathrm{CO}_{2}$ supercritical fluid to obtain $\mathrm{TiO}_{2}$ aerogel.

\section{Characterizations}

A Model Rigaku D/Max-RB powder X-ray diffractometer (XRD, Rigaku, Tokyo, Japan) was operated to analyze the phase structure of our samples. Cu target $\mathrm{K} \alpha$ radiation $(\lambda=0.15406 \mathrm{~nm})$ was adopted in the test, with the $40 \mathrm{kV}$ working voltage and $0.03 \mathrm{~A}$ current. The scanning step was adopted with the step length of $0.08^{\circ}$ and the scanning range of the diffraction angle of $10^{\circ} \sim 80^{\circ}$. The morphology was observed by a Philips XL30FEG scanning electron microscope (SEM, Royal Philips Electronics, Amsterdam, Netherlands) with an acceleration voltage of $10 \mathrm{kV}$; the sample was subject to gilding before observation. Transmission electron microscopy (TEM) was conducted with a Model JEM-2100 electron microscope (JEOL Corp, Tokyo, Japan) operating at $200 \mathrm{keV}$. Fourier Transform infrared spectra were recorded by a Bruker TENSOR27 spectrometer (FTIR, Bruker, Germany) from 4000 to $400 \mathrm{~cm}^{-1}$. Nitrogen adsorption-desorption isotherms were measured at liquid nitrogen temperature $(77 \mathrm{~K})$ by a Quantachrome Autosorb-1MP analyzer (Quantachrome, Boynton Beach, FL, United States) after the samples were degassed in a vacuum at $100^{\circ} \mathrm{C}$ for at least $12 \mathrm{~h}$. The specific surface area was calculated by Brunaur-Emmett-Teller (BET) method. The absorption spectra of all the samples were measured using a UV/vis/NIR spectrophotometer (UV-Vis, Jasco V-570, Japan).

\section{RESULTS AND DISCUSSION}

\section{Appearance and Structural Characterization}

In our work, five different $\mathrm{TiO}_{2}$ aerogels were prepared according to varying amounts of CTAB named CTAB-n $(n=0,1,2,3,4$, as shown in Table 1), respectively. Here, m(CTAB):m( $\left(\mathrm{Ti}\left(\mathrm{OC}_{4} \mathrm{H}_{9}\right)_{4}\right)$ 
TABLE 1 | Parameters of different $\mathrm{TiO}_{2}$ aerogels.

\begin{tabular}{|c|c|c|c|c|c|}
\hline Sample & СТAB (g) & m(CTAB):m(Ti(OC $\left.\left.{ }_{4} \mathrm{H}_{9}\right)_{4}\right)$ & Density $\left(\mathrm{mg} / \mathrm{cm}^{3}\right)$ & Diameter (mm) & $\begin{array}{c}\text { Linear shrinkage } \\
\text { ratio (\%) }\end{array}$ \\
\hline CTAB-0 & 0 & 0 & $251.2 \pm 8.1$ & 14.87 & 62.8 \\
\hline CTAB-1 & 0.1095 & 0.009 & $246.7 \pm 9.4$ & 17.87 & 55.3 \\
\hline CTAB-2 & 0.5475 & 0.046 & $220.7 \pm 8.2$ & 18.45 & 53.9 \\
\hline CTAB-3 & 1.0950 & 0.091 & $175.8 \pm 5.2$ & 20.66 & 48.4 \\
\hline CTAB-4 & 1.6425 & 0.137 & $215.3 \pm 7.7$ & 21.64 & 45.9 \\
\hline
\end{tabular}

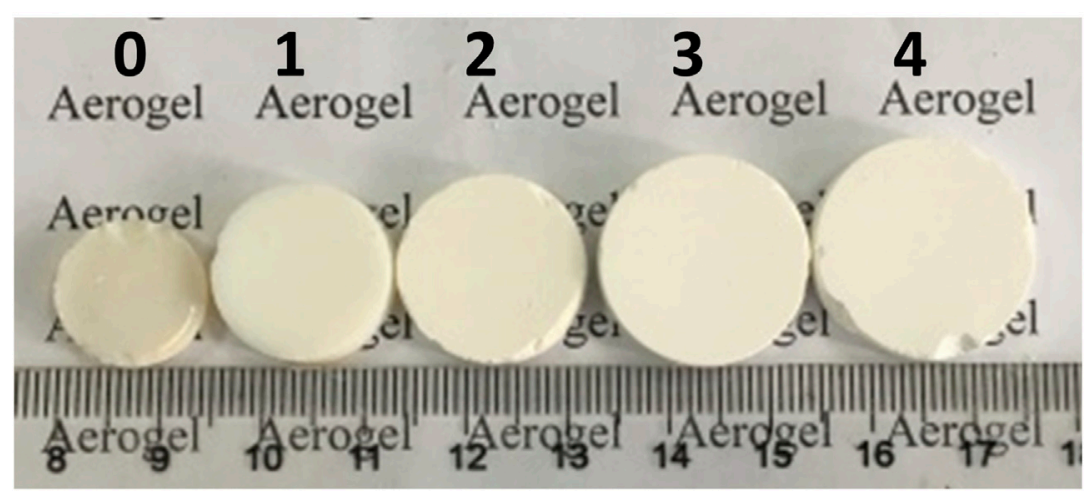

FIGURE 1 | Appearances of five $\mathrm{TiO}_{2}$ aerogels with different additions of CTAB.

was determined by $\mathrm{m}(\mathrm{CTAB}) / \mathrm{m}\left(\mathrm{Ti}\left(\mathrm{OC}_{4} \mathrm{H}_{9}\right)_{4}\right)$, where $\mathrm{m}(\mathrm{CTAB})$ and $\mathrm{m}\left(\mathrm{Ti}\left(\mathrm{OC}_{4} \mathrm{H}_{9}\right)_{4}\right)$ were the mass of added CTAB and the mass of tetrabutyl titanate during the sol-gel process. All of the samples obtained had monolithic appearances of regular cylinders. The bulk density of samples was determined by the weighting method. Table 1 lists their average values of densities, diameters and linear shrinkage ratios after repeated measurements. The linear shrinkage ratio was determined by $100 \times\left(D_{C}-D_{S}\right) / D_{C}$, where $D_{C}$ and $D_{S}$ were the diameters of the container $(40 \mathrm{~mm})$ and the $\mathrm{TiO}_{2}$ aerogels, respectively. It indicated that the shrinkage ratio of monolithic $\mathrm{TiO}_{2}$ aerogels modified by CTAB decreased by up to $\sim 26.9 \%$, compared with pure $\mathrm{TiO}_{2}$ aerogels (CTAB-0). Figure 1 shows the appearances of five different $\mathrm{TiO}_{2}$ aerogels. It was obviously observed that the more $\mathrm{CTAB}$ was added, the less shrinkage the $\mathrm{TiO}_{2}$ aerogels had. Supplementary Figure S1 shows the diameter comparison of five $\mathrm{TiO}_{2}$ aerogels with pure $\mathrm{TiO}_{2}$ aerogel (CTAB-0) as the reference, which is much easier for us to understand the effect of CTAB.

The XRD analysis results are shown in Figure 2 . The diffraction peaks, located at $2 \theta=25.281^{\circ}, 37.800^{\circ}, 48.049^{\circ}$, $53.890^{\circ}, 55.060^{\circ}, 62.119^{\circ}$, and $75.029^{\circ}$, were detected and indexed as anatase- $\mathrm{TiO}_{2}$ phase (PDF No. 21-1272). With acetonitrile as the solvent, the $\mathrm{TiO}_{2}$ aerogels obtained have good crystallinity. Studies show that the calcination temperature obviously effects the phase formation (Qin et al., 2013; Zirakjou et al., 2015; Topcu et al., 2016). With ethanol as the solvent, it is amorphous $\mathrm{TiO}_{2}$ aerogel if the calcination temperature is below $200^{\circ} \mathrm{C}$ (Qingge et al., 2018). Normally, the temperature should be above $450^{\circ} \mathrm{C}$ to obtain anatase

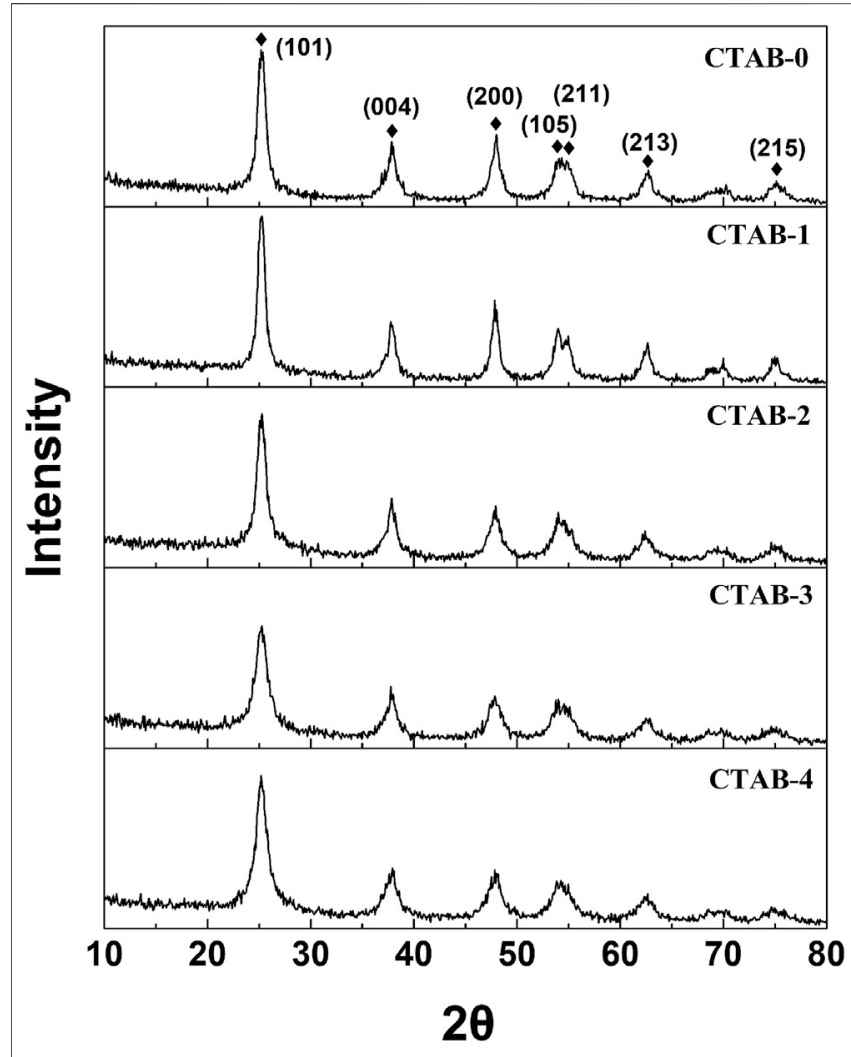

FIGURE 2 | XRD spectra of five $\mathrm{TiO}_{2}$ aerogels. 


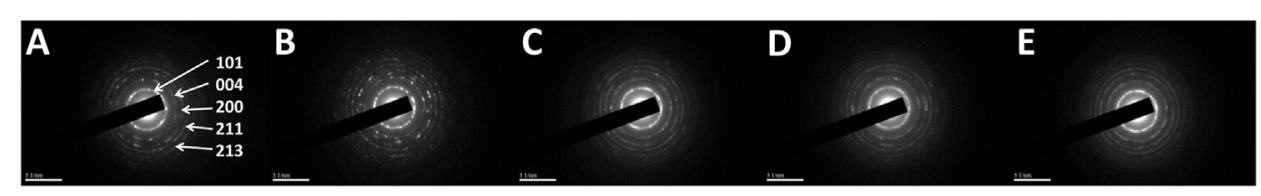

FIGURE 3 | SAED patterns of CTAB-0 (A), 1 (B), 2 (C), 3 (D), 4 (E).
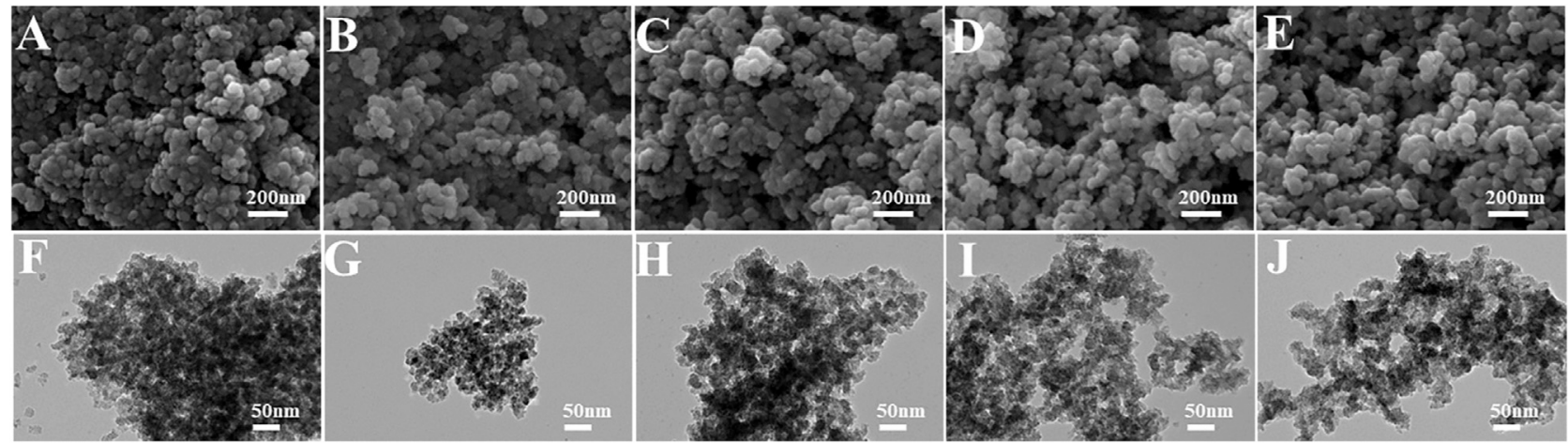

FIGURE 4 | SEM diagrams (A-E) and TEM images (F-J) of five different aerogels (CTAB-0, 1, 2, 3, 4), respectively.

$\mathrm{TiO}_{2}$. However, in our work, even though the $\mathrm{TiO}_{2}$ aerogels didn't be calcined, the typical (101), (004), (200), (105), (211), (213), and (215) diffraction peaks were easily found, which indicated that using acetonitrile as the solvent was beneficial to improve the crystallinity. Meanwhile, the SAED (selected area electron diffraction) patterns (Figure 3) show a series of concentric diffraction rings corresponding to the Miller indices of the tetragonal lattice of the anatase- $\mathrm{TiO}_{2}$ phase, consistent with the XRD results. In order to study the functional groups of these samples, the FTIR technique was carried out and the spectra are shown in Supplementary Figure S2. According to the FTIR spectra, the broadband at $3,424 \mathrm{~cm}^{-1}$ could be ascribed to the $\mathrm{O}-\mathrm{H}$ stretching vibration of absorbed water attached to the surface, whereas the peaks at $1,630 \mathrm{~cm}^{-1}$ could be assigned to the bending vibrations of $\mathrm{O}-\mathrm{H}$ (Chellappa et al., 2015; Yao et al., 2015). The presence of peak at $1,047 \mathrm{~cm}^{-1}$ was possibly due to the adsorbed water molecules. The characteristic absorption peak of $\mathrm{CO}_{3}^{2-}$ appears at $1,385 \mathrm{~cm}^{-1}$, which indicated that $\mathrm{CO}_{2}$ adsorbed on the surface of $\mathrm{TiO}_{2}$ reacted with $\mathrm{H}_{2} \mathrm{O}$ to form $\mathrm{CO}_{3}^{2-}$ (Bezrodna et al., 2004; Wu et al., 2018). The band at $900-500 \mathrm{~cm}^{-1}$ was attributed to the vibrations of Ti-O-Ti bonds (Wen and Zhang, 2016; Feizpour et al., 2019; Jnido et al., 2019).

\section{Morphology and Microstructure Analysis}

Figure 4 shows the SEM diagrams (A-E) and the TEM images (F-J) of five different aerogels (CTAB-0, 1, 2, 3, 4), respectively. All the $\mathrm{TiO}_{2}$ aerogels exhibited random nanoporous network structures, which consisted of regular spherical or near-spherical clusters and irregular pores. With the addition of CTAB, the aggregation of nanoparticles and the collapse of the network were reduced, which was in accordance with the appearance analysis.

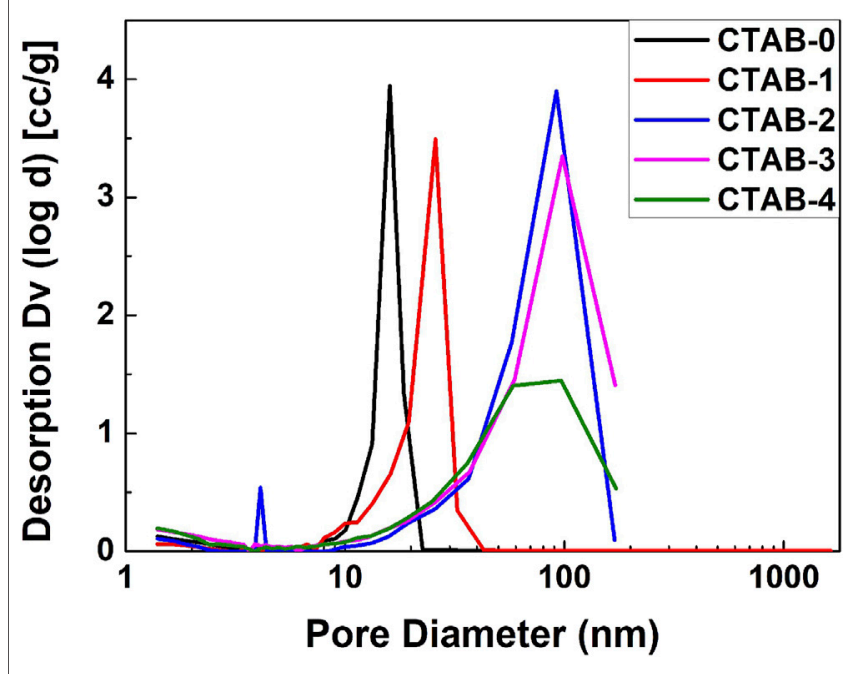

FIGURE 5 | Comparison of the pore size distributions.

The nitrogen adsorption/desorption isotherms of five assynthesized $\mathrm{TiO}_{2}$ aerogels are shown in Supplementary Figure S3. Based on the BJH (Barrett-Joyner-Halenda model) analysis on the desorption curves, their pore-size distributions are compared in Figure 5. Table 2 lists the specific surface areas, the average diameters, and the total volumes. According to the pore distribution and the data related to the pore structures, it is easily summarized that the addition of CTAB is beneficial to the increase of the pore size. But in our work, there is a suitable value of the $\mathrm{CTAB}$ adding amount. Here, the recipe of CTAB-3 
TABLE 2 | Data related to the pore structures of five $\mathrm{TiO}_{2}$ aerogels.

\begin{tabular}{|c|c|c|c|}
\hline Sample & $\begin{array}{c}\text { Specific } \\
\text { surface area }\left(\mathrm{m}^{2} / \mathrm{g}\right)\end{array}$ & $\begin{array}{c}\text { Average } \\
\text { pore diameter }(\mathrm{nm})\end{array}$ & Total pore Volume $\left(\mathrm{cm}^{3} / \mathrm{g}\right)$ \\
\hline CTAB-0 & 264.8 & 9.38 & 0.6207 \\
\hline CTAB-1 & 199.2 & 16.63 & 0.8282 \\
\hline CTAB-2 & 210.1 & 27.14 & 1.426 \\
\hline CTAB-3 & 250.2 & 27.50 & 1.720 \\
\hline CTAB-4 & 230.0 & 19.35 & 1.113 \\
\hline
\end{tabular}
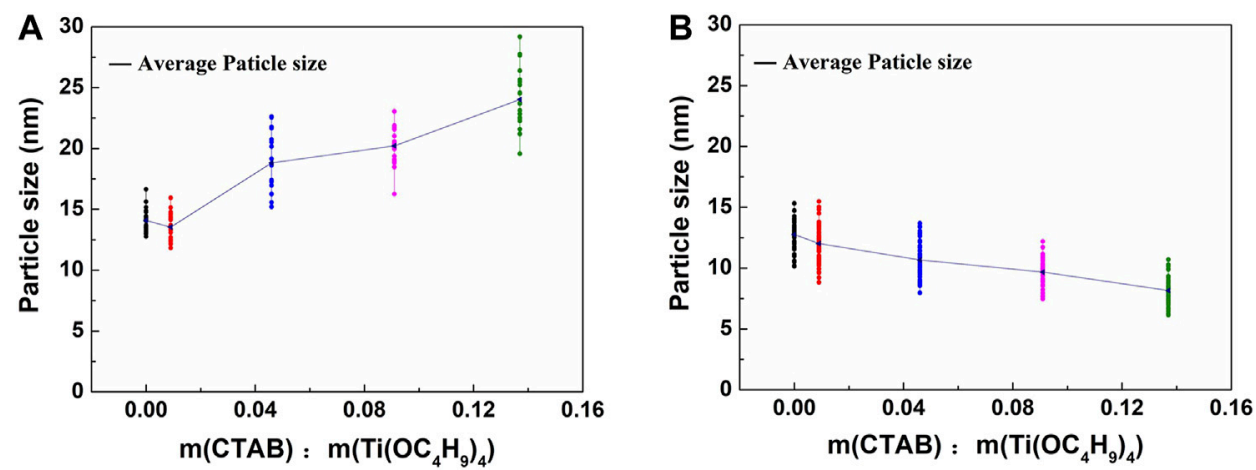

FIGURE 6 | Particle size measurements of $\mathbf{( A )} \mathrm{TiO}_{2}$ aerogels without the calcination, (B) $300^{\circ} \mathrm{C}$-calcined $\mathrm{TiO}_{2}$ aerogels.

was considered as a better choice because the sample has a lower density and a better nanoporous network structure.

\section{Structure-Property Relationship}

To further study the role of CTAB, these five $\mathrm{TiO}_{2}$ aerogels were placed in a muffle furnace at $300^{\circ} \mathrm{C}$ for $1 \mathrm{~h}$ with a heating rate of $3^{\circ} \mathrm{C} /$ min. The calcined $\mathrm{TiO}_{2}$ aerogels were also characterized by $\mathrm{X}$-ray diffraction (XRD), a scanning electron microscope (SEM), a transmission electron microscope (TEM), and specific surface area analysis (BET). The results are shown in detail in the Supplementary Material. Supplementary Figures S4, S5 indicated that the $300^{\circ} \mathrm{C}$-calcined $\mathrm{TiO}_{2}$ aerogels were anatase$\mathrm{TiO}_{2}$ phase (PDF No. 21-1272) and had higher crystallinities. However, there were apparent particle agglomeration and collapse of the network according to the results of SEM (Supplementary Figure S6), TEM (Supplementary Figure S6), and BET (Supplementary Figures S7, S8; Supplementary Table S1).

The particle sizes of as-synthesized and $300^{\circ} \mathrm{C}$-calcined aerogels were evaluated by measuring the diameters of particles (50 measurements for each sample) in TEM images. Supplementary Figures S9, S10 were two examples of the measurements. Besides, the crystallite sizes of these two types of aerogels were calculated by the Scherrer formula (Gnaser et al., 2011; Suryanarayana et al., 2011; Sharma et al., 2019; Dong et al., 2020). Here, we chose the typical (101), (004), (200), and (213) diffraction peaks to compare the size in different crystal plane orientations. According to the comparisons in Figures 6, 7, for aerogels that have not been heat-treated, the particle size and crystal grain size showed the opposite changing trends. In contrast, the calcined samples showed a similar changing trend. It was likely that CTAB was coated on the outside of the $\mathrm{TiO}_{2}$ particles.
The more $\mathrm{CTAB}$ was added, the thicker the coating layer was. This may explain the result in Figure 6A. In this case, the coating of $\mathrm{CTAB}$ could also strengthen the nano-skeleton structure and improve the moldability of the $\mathrm{TiO}_{2}$ aerogels. Figure 7 confirmed that the more CTAB was added, the smaller the $\mathrm{TiO}_{2}$ crystal particles grew. It is possible that the coating of CTAB could limit the growth of $\mathrm{TiO}_{2}$ particles to a certain extent. This effect of grain refinement is beneficial to the photocatalysis (Luna et al., 2020).

To further study the structure-property relationship, the photocatalysis performance of as-synthesized and $300^{\circ} \mathrm{C}$ calcined aerogels was carried out contrastively. The degradations of gentian violet $(\mathrm{GV})$ and methylene blue (MB) were both tested. $10 \mathrm{mg}$ of $\mathrm{TiO}_{2}$ aerogel was dispersed in $40 \mathrm{ml}$ of dye solution (GV or MB, $20 \mathrm{mg} / \mathrm{L}$ ) and placed in the dark for $1 \mathrm{~h}$ before UV-light irradiation. Then the dye solution in presence of $\mathrm{TiO}_{2}$ aerogel was exposed under a UV lamp for $120 \mathrm{~min}$. The absorption spectra of the dye solution were measured by a UV/ vis/NIR spectrophotometer. Figure 8 shows the dye solution concentration percentages, which present the photocatalysis performance of different aerogels. Here, $\mathrm{C}_{0}$ and $\mathrm{C}$ were the initial dye solution concentration $(20 \mathrm{mg} / \mathrm{L})$ and the final dye solution concentration after UV-light irradiation. Meanwhile, the adsorptions of dye solution ( $\mathrm{GV}$ or $\mathrm{MB}, 20 \mathrm{mg} / \mathrm{L}$ ) for all the assynthesized and $300^{\circ} \mathrm{C}$-calcined aerogels were measure as well and the results are shown in Supplementary Figure S11. The degradation rate curves with time of CTAB-0 and CTAB-4-300 are compared in Supplementary Figure S12, which are consistent with the results in Figure 8. Interestingly, the influences of the CTAB amount of as-synthesized and calcined $\mathrm{TiO}_{2}$ aerogels were negative and positive, respectively, which is 

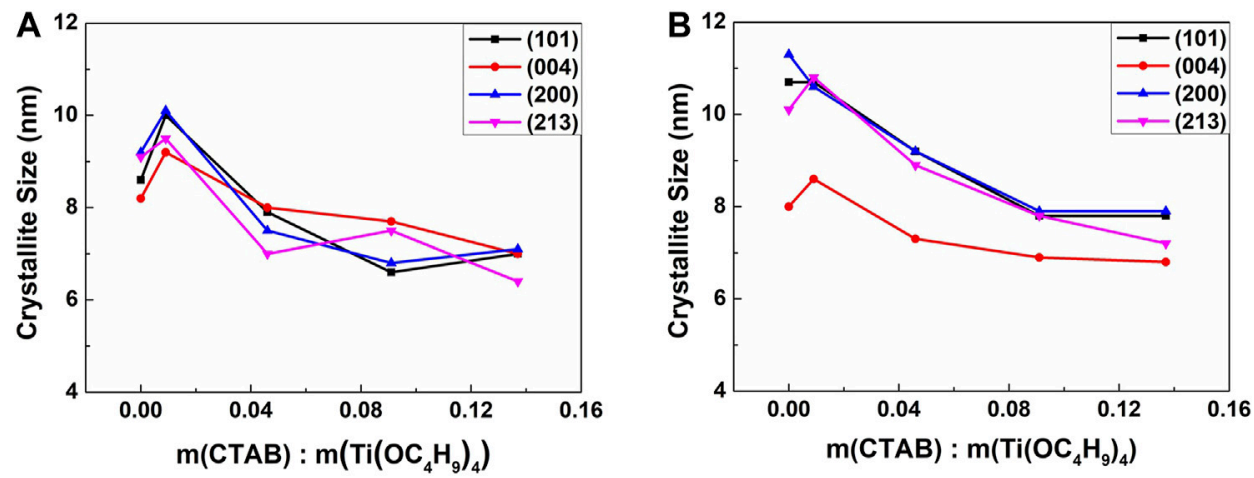

FIGURE 7 | Crystallite size analysis of (A) $\mathrm{TiO}_{2}$ aerogels without the calcination, (B) $300^{\circ} \mathrm{C}$-calcined $\mathrm{TiO}_{2}$ aerogels.
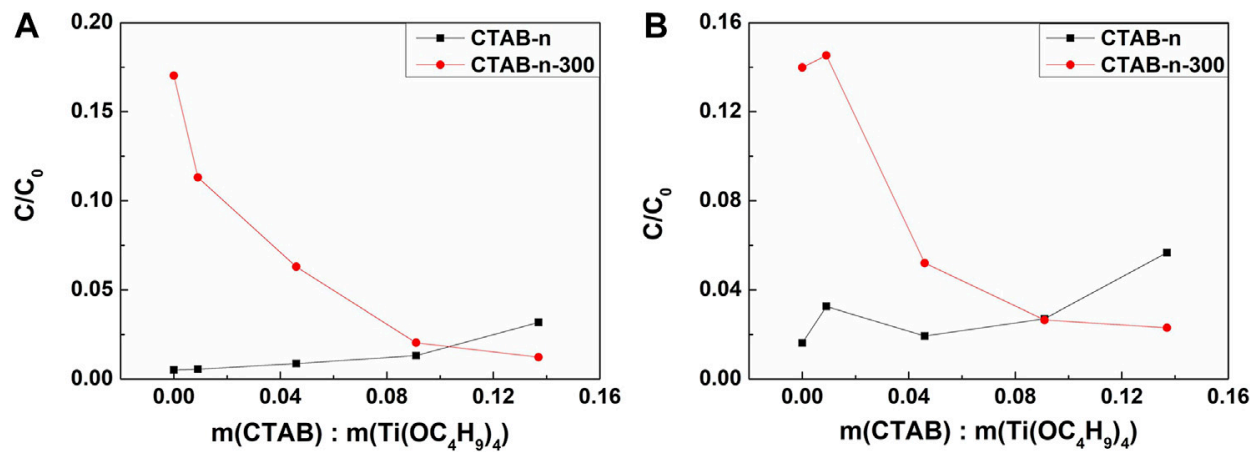

FIGURE 8 | (A) The GV concentration percentage after exposure to irradiation for 120 min; (B) the MB concentration percentage after exposure to irradiation for $120 \mathrm{~min}$.

probably due to the synergistic effect of $\mathrm{CTAB}$ hindrance and grain refinement. In other words, with the increase of CTAB added, the photocatalysis of uncalcined samples became worse. However, as for the calcined samples, due to the addition of $\mathrm{CTAB}$, the grain size could become smaller, thereby contributing to photocatalysis. Therefore, the performance of photocatalytic performance may be influenced by the combination of the two above effects. As a result, the CTAB-3 $\mathrm{TiO}_{2}$ aerogel was considered as a suitable choice because it had good performance of photocatalysis with finer crystalline grain, lower density, higher specific surface area, and better formability. What's more, this kind of monolithic $\mathrm{TiO}_{2}$ aerogel with low density is a perfect template to prepare the selfsupporting nanoporous titanium aerogel (Xu et al., 2016).

\section{CONCLUSION}

In our work, we successfully prepared monolithic CTAB-modified $\mathrm{TiO}_{2}$ aerogels without severe shrink using acetonitrile as the solvent to improve the crystallinity. Five $\mathrm{TiO}_{2}$ aerogels were compared to study the effect of the CTAB adding amounts. To further understand the role of $\mathrm{CTAB}$, we discussed the structure-property relationships of the as-synthesized and $300^{\circ} \mathrm{C}$-calcined aerogels. It indicated that the performance of photocatalysis was probably influenced by the synergistic effect of $\mathrm{CTAB}$ hindrance and grain refinement. The CTAB-3 $\mathrm{TiO}_{2}$ aerogel was considered as a good choice with a relatively excellent performance of photocatalysis since it had a lower density $\left(175.8 \mathrm{mg} / \mathrm{cm}^{3}\right)$ and a higher specific surface area $\left(250.2 \mathrm{~m}^{2} /\right.$ g). Potentially, this kind of $\mathrm{TiO}_{2}$ aerogels assisted by CTAB with low density, small shrinkage, improved formability, high specific surface area and fine crystalline grain could play an important part in various applications, such as electrochemistry, photocatalysis, etc.

\section{DATA AVAILABILITY STATEMENT}

The original contributions presented in the study are included in the article/Supplementary Material, further inquiries can be directed to the corresponding authors.

\section{AUTHOR CONTRIBUTIONS}

$\mathrm{BZ}, \mathrm{AD}$, and $\mathrm{TN}$ designed the study. $\mathrm{TN}$ carried out the experiments and wrote the original draft manuscript. TN and 
ZeZ carried out the characterization tests with the support of $\mathrm{ZhZ}$ and JS. JY and XJ made the data interpretation. BZ and AD revised and approved the submitted version.

\section{FUNDING}

This research is supported by the National Key Research and Development Program of China (2017YFA0204600) and National Natural Science Foundation of China (11874284).

\section{REFERENCES}

Anucha, C. B., Altin, I., Bacaksız, E., Kucukomeroglu, T., Belay, M. H., and Stathopoulos, V. N. (2021). Enhanced Photocatalytic Activity of CuWO4 Doped TiO2 Photocatalyst towards Carbamazepine Removal under UV Irradiation. Separations 8 (3), 25. doi:10.3390/separations8030025

Baia, L., Peter, A., Cosoveanu, V., Indrea, E., Baia, M., Popp, J., et al. (2006). Synthesis and Nanostructural Characterization of $\mathrm{TiO} 2$ Aerogels for Photovoltaic Devices. Thin Solid Films 511-512, 512-516. doi:10.1016/j.tsf. 2005.12.024

Bathula, C., Rabani, I., Sekar, S., Youi, H.-K., Choy, J.-Y., Kadam, A., et al. (2021). Enhanced Removal of Organic Dye by Activated Carbon Decorated TiO2 Nanoparticles from Mentha Aquatica Leaves via Ultrasonic Approach. Ceramics Int. 47 (6), 8732-8739. doi:10.1016/j.ceramint.2020.12.282

Bezrodna, T., Puchkovska, G., Shymanovska, V., Baran, J., and Ratajczak, H. (2004). IR-analysis of H-Bonded H2O on the Pure TiO2 Surface. J. Mol. Struct. 700 (1-3), 175-181. doi:10.1016/j.molstruc.2003.12.057

Bi, Y., Zhu, J., Xie, Z., and Ren, H. (2019). Uniformly Structured Methyltrimethoxysilane-Based Silica Aerogels with Enhanced Mechanical Property by Surfactant-free Fabrication. Int. J. Nanosci. 19 (03), 1950017. doi:10.1142/s0219581x19500170

Chellappa, M., Anjaneyulu, U., Manivasagam, G., and Vijayalakshmi, U. (2015). Preparation and Evaluation of the Cytotoxic Nature of TiO2 Nanoparticles by Direct Contact Method. Int. J. Nanomedicine 10 Suppl 1 (Suppl. 1), 31-41. doi:10.2147/IJN.S79978

Chen, X. (2009). Titanium Dioxide Nanomaterials and Their Energy Applications. Chin. J. Catal. 30 (8), 839-851. doi:10.1016/s1872-2067(08)60126-6

Cheng, P., Wang, Y., Xu, L., Sun, P., Su, Z., Jin, F., et al. (2016). High Specific Surface Area Urchin-like Hierarchical ZnO-TiO 2 Architectures: Hydrothermal Synthesis and Photocatalytic Properties. Mater. Lett. 175, 52-55. doi:10.1016/j.matlet.2016.03.120

Dong, Y., Zhang, W., and Tao, Y. (2020). CTAB Modified TiO2 Supported on HZSM-5 Zeolite for Enhanced Photocatalytic Degradation of Azophloxine. J. Mater. Res. Technol. 9 (4), 9403-9411. doi:10.1016/j.jmrt.2020.05.091

Feizpour, F., Jafarpour, M., and Rezaeifard, A. (2019). Band Gap Modification of TiO2 Nanoparticles by Ascorbic Acid-Stabilized Pd Nanoparticles for Photocatalytic Suzuki-Miyaura and Ullmann Coupling Reactions. Catal. Lett. 149 (6), 1595-1610. doi:10.1007/s10562-019-02749-Z

Gnaser, H., Lösch, J., Orendorz, A., and Ziegler, C. (2011). Temperature-dependent Grain Growth and Phase Transformation in Mixed Anatase-Rutile Nanocrystalline TiO2 Films. Phys. Status Solidi A. 208 (7), 1635-1640. doi:10.1002/pssa.201026784

Guo, S., Shang, J., Zhao, T., Hou, D., Jin, Z., and Sun, G. (2018). $\mathrm{TiO}_{2} /$ Cyclodextrin Hybrid Structure with Efficient Photocatalytic Water Splitting. ES Mater. Manuf 2, 24-27. doi:10.30919/esmm5f168

Hu, L. L., Yoko, T., Kozuka, H., and Sakka, S. (1992). Effects of Solvent on Properties of Sol Gel-Derived $\mathrm{TiO}_{2}$ Coating Films. Thin Solid Films 219(1-2), 18-23. doi:10.1016/0040-6090(92)90718-Q

Jnido, G., Ohms, G., and Viöl, W. (2019). Deposition of TiO2 Thin Films on Wood Substrate by an Air Atmospheric Pressure Plasma Jet. Coatings 9 (7), 441. doi:10.3390/coatings 9070441

Liu, X., Liu, X., Shan, J., Huai, J., Yang, H., Yan, X., et al. (2021). Synthesis of Amorphous Mesoporous TiO2-SiO2 and its Excellent Catalytic Performance in

\section{ACKNOWLEDGMENTS}

We would like to appreciate all the fellows from our research group.

\section{SUPPLEMENTARY MATERIAL}

The Supplementary Material for this article can be found online at: https://www.frontiersin.org/articles/10.3389/fmats.2021.674578/ full\#supplementary-material

Oxidative Desulfurization. Inorg. Chem. Commun. 123, 108336. doi:10.1016/j. inoche.2020.108336

Luna, A. L., Matter, F., Schreck, M., Wohlwend, J., Tervoort, E., Colbeau-Justin, C., et al. (2020). Monolithic Metal-Containing TiO2 Aerogels Assembled from Crystalline Pre-formed Nanoparticles as Efficient Photocatalysts for $\mathrm{H} 2$ Generation. Appl. Catal. B: Environ. 267, 118660. doi:10.1016/j.apcatb.2020. 118660

Martins, A. C., Cazetta, A. L., Pezoti, O., Souza, J. R. B., Zhang, T., Pilau, E. J., et al. (2017). Sol-gel Synthesis of New TiO 2/activated Carbon Photocatalyst and its Application for Degradation of Tetracycline. Ceramics Int. 43 (5), 4411-4418. doi:10.1016/j.ceramint.2016.12.088

Moussaoui, R., Elghniji, K., ben Mosbah, M., Elaloui, E., and Moussaoui, Y. (2017). Sol-gel Synthesis of Highly TiO2 Aerogel Photocatalyst via High Temperature Supercritical Drying. J. Saudi Chem. Soc. 21 (6), 751-760. doi:10.1016/j.jscs. 2017.04.001

Muniz, E. C., Góes, M. S., Silva, J. J., Varela, J. A., Joanni, E., Parra, R., et al. (2011). Synthesis and Characterization of Mesoporous TiO2 Nanostructured Films Prepared by a Modified Sol-Gel Method for Application in Dye Solar Cells. Ceramics Int. 37 (3), 1017-1024. doi:10. 1016/j.ceramint.2010.11.014

Nadrah, P., Gaberšček, M., and Sever Škapin, A. (2017). Selective Degradation of Model Pollutants in the Presence of Core@shell TiO2@SiO2 Photocatalyst. Appl. Surf. Sci. 405, 389-394. doi:10.1016/j.apsusc.2017.02.058

Noman, M. T., Ashraf, M. A., and Ali, A. (2019). Synthesis and Applications of Nano-TiO2: a Review. Environ. Sci. Pollut. Res. 26 (4), 3262-3291. doi:10.1007/ s11356-018-3884-z

Parale, V. G., Kim, T., Phadtare, V. D., Yadav, H. M., and Park, H.-H. (2019). Enhanced Photocatalytic Activity of a Mesoporous TiO2 Aerogel Decorated onto Three-Dimensional Carbon Foam. J. Mol. Liquids 277, 424-433. doi:10. 1016/j.molliq.2018.12.080

Qin, M., Zhao, W., Chu, J., Qu, J., Wang, L., Li, S., et al. (2013). Synthesis and Characterization of Mesoporous TiO2 Prepared via Three Different Procedures in Ethanol Medium. Mater. Res. Bull. 48 (3), 1076-1081. doi:10.1016/j. materresbull.2012.11.108

Qingge, F., Huidong, C., Haiying, L., Siying, Q., Zheng, L., Dachao, M., et al. (2018). Synthesis and Structural Characteristics of High Surface Area TiO2 Aerogels by Ultrasonic-Assisted Sol-Gel Method. Nanotechnology 29 (7), 075702. doi:10. 1088/1361-6528/aaald1

Sanjay, P., .Deepa, K., Merline Shyla, J., Madhavan, J., and Senthil, S. (2019). Performance of TiO2 Based Dye-Sensitized Solar Cells Fabricated Using Coomassie Brilliant Blue in Acetonitrile Solution. Mater. Today Proc. 8, 130-135. doi:10.1016/j.matpr.2019.02.090

Sharma, R., Sarkar, A., Jha, R., Kumar Sharma, A., and Sharma, D. (2019). Sol-gelmediated Synthesis of TiO 2 Nanocrystals: Structural, Optical, and Electrochemical Properties. Int. J. Appl. Ceram. Technol. 17 (3), 1400-1409. doi:10.1111/ijac.13439

Suryanarayana, C., Mukhopadhyay, D., Patankar, S. N., and Froes, F. H. (2011). Grain Size Effects in Nanocrystalline Materials. J. Mater. Res. 7 (8), 2114-2118. doi:10.1557/jmr.1992.2114

Topcu, S., Jodhani, G., and Gouma, P. I. (2016). Optimized Nanostructured TiO2 Photocatalysts. Front. Mater. 3, 35. doi:10.3389/fmats.2016.00035

Wen, X., and Zhang, H. (2016). Photoelectrochemical Properties of CuS-GeO2TiO2 Composite Coating Electrode. PLoS One 11 (4), e0152862. doi:10.1371/ journal.pone.0152862 
Wen, S., Ren, H., Zhu, J., Bi, Y., and Zhang, L. (2018). Fabrication of $\mathrm{Al} 2 \mathrm{O} 3$ Aerogel-SiO2 Fiber Composite with Enhanced thermal Insulation and High Heat Resistance. J. Porous Mater. 26 (4), 1027-1034. doi:10.1007/ s10934-018-0700-6

Wen, S., Zhu, J., Yin, Q., Bi, Y., Ren, H., and Zhang, L. (2020). Fabrication of Infrared Opacifiers Loaded Al2O3 Aerogel-SiO2 Fiber Mat Composites with High Thermal Resistance. Int. J. Nanosci. 19 (03), 1950021. doi:10.1142/ s0219581x19500212

Wu, W., Zhang, L., Zhai, X., Liang, C., and Yu, K. (2018). Preparation and Photocatalytic Activity Analysis of Nanometer TiO2 Modified by Surfactant. Nanomater. Nanotechnol. 8, $\quad 184798041878197 . \quad$ doi:10.1177/ 1847980418781973

Xiang, C., Guo, R., Lan, J., Jiang, S., Wang, C., Du, Z., et al. (2018). Self-assembling Porous 3D Titanium Dioxide-Reduced Graphene Oxide Aerogel for the Tunable Absorption of Oleic Acid and RhodamineB Dye. J. Alloys Compd. 735, 246-252. doi:10.1016/j.jallcom.2017.11.034

Xie, L., Li, Z., Sun, L., Dong, B., Fatima, Q., Wang, Z., et al. (2019). Sol-gel Synthesis of $\mathrm{TiO} 2$ with P-type Response to Hydrogen Gas at Elevated Temperature. Front. Mater. 6. doi:10.3389/fmats.2019.00096

Xu, W., Du, A., Xiong, J., Zhang, Z., Shen, J., and Zhou, B. (2016). Freestanding Titanium Metallic Aerogel. Mater. Des. 97, 93-97. doi:10.1016/j.matdes.2016. 02.070

Yan, L., Ren, H., Zhu, J., Bi, Y., and Zhang, L. (2018). One-step Eco-Friendly Fabrication of Classically Monolithic Silica Aerogels via Water Solvent System and Ambient Pressure Drying. J. Porous Mater. 26 (3), 785-791. doi:10.1007/ s10934-018-0674-4

Yao, P., Zhong, S., and Shen, Z. (2015). TiO2/Halloysite Composites Codoped with Carbon and Nitrogen from Melamine and Their Enhanced Solar-Light-Driven Photocatalytic Performance. Int. J. Photoenergy 2015, 1-8. doi:10.1155/2015/ 605690
Zhang, B.-x., Yu, H., Zhang, Y., Luo, Z., Han, W., Qiu, W., et al. (2018). Bacterial Cellulose Derived Monolithic Titania Aerogel Consisting of 3D Reticulate Titania Nanofibers. Cellulose 25 (12), 7189-7196. doi:10.1007/s10570-0182073-z

Zhong, J. b., Li, J. z., Feng, F. m., Huang, S. t., and Zeng, J. (2013). CTAB-assisted Fabrication of TiO2 with Improved Photocatalytic Performance. Mater. Lett. 100, 195-197. doi:10.1016/j.matlet.2013.03.030

Zirakjou, A., Aghdam, R. M., and Soorbaghi, F. P. (2015). Synthesis and Characterization of Monolithic Titania/Nanoclay Nanocomposite Aerogels. Proced. Mater. Sci. 11, 548-552. doi:10.1016/j.mspro.2015.11.054

Znaidi, L., Séraphimova, R., Bocquet, J. F., Colbeau-Justin, C., and Pommier, C. (2001). A Semi-continuous Process for the Synthesis of Nanosize TiO2 Powders and Their Use as Photocatalysts. Mater. Res. Bull. 36, 811-825. doi:10.1016/ s0025-5408(00)00482-7

Zu, G., Shen, J., Wang, W., Zou, L., Lian, Y., and Zhang, Z. (2015). Silica-titania Composite Aerogel Photocatalysts by Chemical Liquid Deposition of Titania onto Nanoporous Silica Scaffolds. ACS Appl. Mater. Inter. 7 (9), 5400-5409. doi:10.1021/am5089132

Conflict of Interest: The authors declare that the research was conducted in the absence of any commercial or financial relationships that could be construed as a potential conflict of interest.

Copyright (c) $2021 \mathrm{Niu}$, Zhou, Zhang, Yang, Ji, Shen, Zhang and Du. This is an openaccess article distributed under the terms of the Creative Commons Attribution License (CC BY). The use, distribution or reproduction in other forums is permitted, provided the original author(s) and the copyright owner(s) are credited and that the original publication in this journal is cited, in accordance with accepted academic practice. No use, distribution or reproduction is permitted which does not comply with these terms. 